\title{
Cytotaxonomic Studies on Chilean Galaxiid Fishes. The Karyotypes, C-bands, Ag-NORs and Hybrids of Brachygalaxias gothei and B. bullocki (Osteichthyes: Galaxiidae)
}

\author{
C. C. Cuevas ${ }^{1 *}$, H. H. Campos ${ }^{\dagger}$ and K. Busse ${ }^{2}$ \\ ${ }^{1}$ Instituto de Zoología, Universidad Austral de Chile, Casilla 567, Valdivia Chile \\ ${ }^{2}$ Forschunginstitut und Museum Alexander Koenig, \\ Adenaueralle 16053113 Bonn, Germany \\ Accepted July 7, 1999
}

\begin{abstract}
Summary The cytogenetic analysis of Brachygalaxias gothei, B. bullocki and their hybrids showed differences in the number of biarmed and monoarmed chromosomes, as like as, in their c-banding patterns. The basic karyotype consists in $2 \mathrm{n}=40$ with a $\mathrm{FN}=58$ in $B$. gothei, and 66 in $B$. bullocki, and $2 \mathrm{n}=38+1$ and $\mathrm{FN}=51$ in the hybrids. B. bullocki presents a larger quantity of constitutive heterochromatin than $B$. gothei, and present a polymorphism in the location of one pair of NOR. The taxonomic status of $B$. gothei is discussed in relation of chromosome results and the hybrid sterility.
\end{abstract}

Key words Fish cytogenetics, Hybrids, Galaxiids, Chile.

The fresh-waters fishes of the genus Brachygalaxias (Galaxiidae) are typical inhabitants of the limnetycal environments of southern Chile (ca. 38-42 ${ }^{\circ} \mathrm{S}$, Arratia 1981). Two species (B. bullocki, $38.9 \mathrm{~mm}$ standard length, $B$. gothei, $28.8 \mathrm{~mm}$ standard length), have been described in this genus. Both taxa can be distinguished on the basis of spawning colour patterns of males, and morphometric characteristics (Busse 1982, 1983). Using a statistical approach (principal component analysis), Berra et al. (1995) concluded that $B$. gothei should be considered a junior synonym of $B$. bullocki.

Different authors have studied cytological characteristics (chromosomes) in order to solve taxonomic problems in fishes (Caputo et al. 1996, Karakousis and Rabova 1996, Phillips et al. 1989). This approach is here used to establish the taxonomic status of $B$. gothei. We assume that $B$. gothei and $B$. bullocki constitute different entities, and as a consequence, we expect that do not share same karyological pattern. In addition, it must be expected that the hybrids resulting from both species would show an intermediate karyotype respect to the parents, and high degree of sterility. In this paper we describe for the first time the karyological patterns (karyotypes, C-band, Ag-NORs) of $B$. gothei, and the hybrids between $B$. gothei and B. bullocki. Additionally the karyotype of B. bullocki is redescribed because our results are not in agreement with Campos (1972) description.

Materials and methods

\section{Analyzed animals}

Chromosomes of 9 mature specimens of Brachygalaxias gothei (5 males and 4 females) from the basin of the Maule River $\left(35^{\circ} 23^{\prime} \mathrm{S}, 71^{\circ} 40^{\prime} \mathrm{W}\right)$, were studied. 17 specimens of $B$. bullocki, 7 ( 1 female and 6 males) from the Chada bridge ( $20 \mathrm{~km}$ from the type locality) $\left(38^{\circ} 46^{\prime} \mathrm{S}, 72^{\circ} 37^{\prime} \mathrm{W}\right)$, and 10 ( 7 females and 3 males) from Saval Park $\left(39^{\circ} 48^{\prime} \mathrm{S}, 73^{\circ} 14^{\prime} \mathrm{W}\right)$ (Valdivia) were analyzed (Fig. 1). In addition, 3 hybrids ( 1 male, 2 females), obtained in an artificial pond exposed to natural condi-

\footnotetext{
* Corresponding author, E-mail: ccuevas@valdivia.uca.uach.cl., ${ }^{\dagger}$ In memoriam
} 




Fig. 1. Map of central south of Chile showing the locations where B. gothei and B. bullocki were collected.

tions $\left(5^{\circ} \mathrm{C}\right)$ from both species $(B$. bullocki male $\times$ B. gothei female), in Bonn, Germany, were also studied. As control either parental species was reared under similar conditions in other artificial ponds in conspecific breeding groups. The specimens of $B$. gothei and the hybrids were deposited in the fish collection of the Alexander Köenig Research Institute and Museum of Zoology (ZFMK), Bonn, Germany. The specimens of B. bullocki were deposited in the fish collection of the Zoology Institute in the Austral University of Chile.

\section{Cytogenetic methods}

In order to obtain metaphasic chromosomes, specimens were injected with colchicine $0.5 \%$ $(0.02 \mathrm{ml}$ per $1 \mathrm{gr}$ of animal weight) $5 \mathrm{~h}$ before extracting the intestines (Amemiya et al. 1984 , Gold et al. 1990). Since each specimen had about $0.3 \mathrm{~g}$ each one was injected with $7 \mu 1$ of colchicine. Relative length (RL) of the chromosome was obtained according to Bogart (1970), and their morphology were classified according to centromeric position in metacentric $(\mathrm{m})$, submetacentric ( $\mathrm{sm}$ ), telocentric (t) and subtelocentric (st) sensu Levan et al. (1964). The c-banding and the NOR (nucleolus organizer region) techniques were developed according Sumner (1972) and Rufas et al. (1982) respectively, lightly modified by Cuevas and Formas (1996). The preparations of chromosomes were deposited in the Zoology Institute of the Austral University of Chile.

\section{Results}

\section{Brachygalaxias gothei: Karyotype}

The analysis of 79 metaphasic plates showed that the modal diploid number (2n) in both sexes 


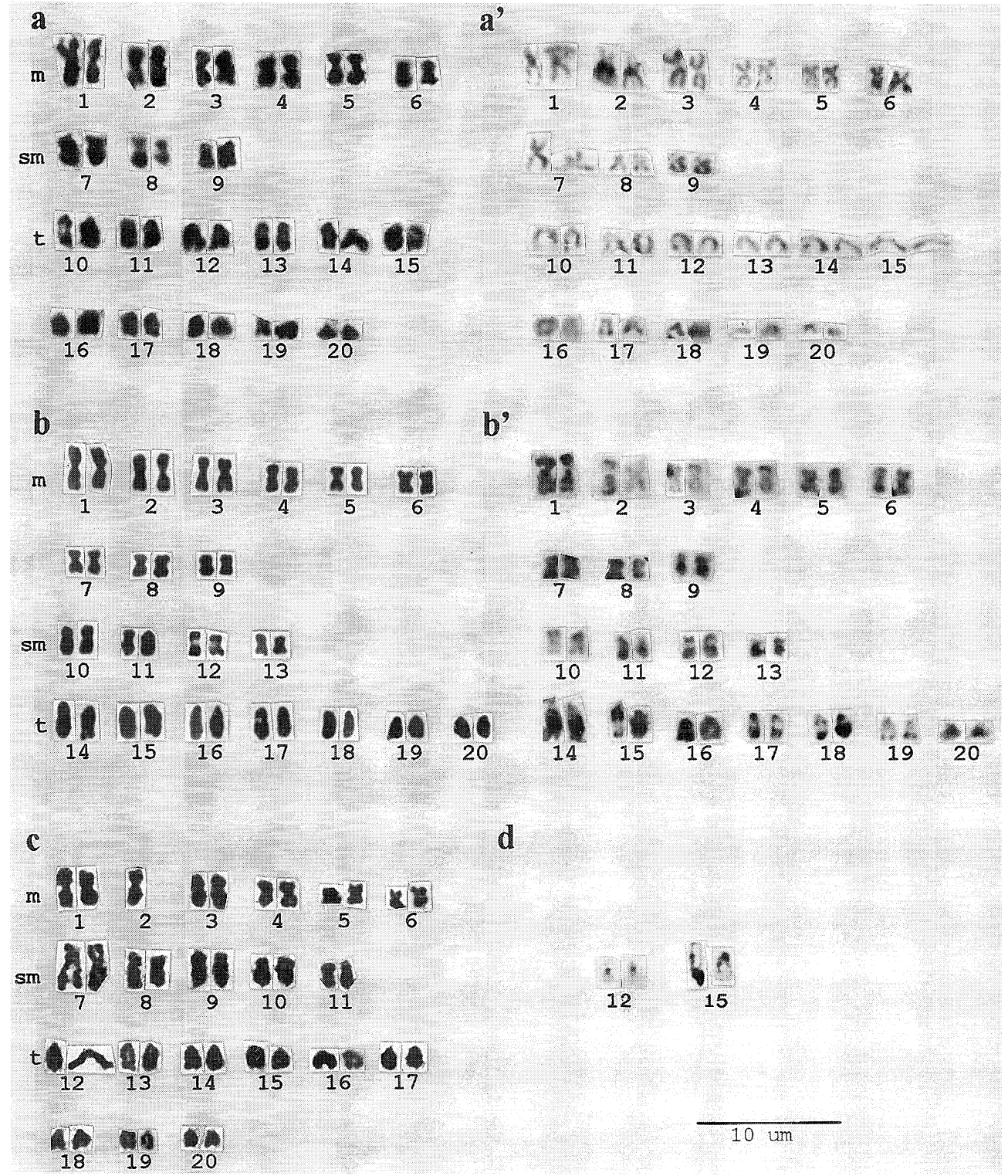

Fig. 2. Karyotype of B. gothei. a) normal, a') c-band, b) Karyotype of B. bullocki, normal, b') c-band, c) Karyotype of the hybrids $\left(\mathrm{F}_{1}\right)$, d) Active AgNOR locations in B. bullocki.

of this species was $2 \mathrm{n}=40$, and the karyotype comprised 18 biarmed and 22 monoarmed chromosomes. The measurements obtained from ten metaphasic plates of $B$. gothei showed that the biarmed chromosomes are divided in 6 metacentric pairs (the pairs 1 to 6) and 3 submetacentric pairs (the pairs 7 to 9). The pairs 10 to 20 are telocentric, and a remarkable secondary constriction is present in the short arm of the pair 8 (Fig. 2a, Table 1). The fundamental number (FN) is 58, and heteromorphic sex chromosomes were not detected.

B. gothei: C-banding and Ag-NORs

The C-banded karyotype exhibits constitutive heterochromatin in the pericentromeric region of the chromosome pairs number 1, 2, 18 in both males and females (Fig. 2a'). The intensity of stained 
Table 1. Summary of the relative length (RL), centromeric ratio (CR) and types of chromosomes of Brachygalaxias gothei, B. bullocki and the hybrids $\left(\mathrm{F}_{1}\right)$ between these two species. Standard deviation (SD).

\begin{tabular}{|c|c|c|c|c|c|c|c|c|c|}
\hline \multirow{2}{*}{ Pair } & \multicolumn{3}{|c|}{ Brachygalaxias gothei } & \multicolumn{3}{|c|}{ Brachygalaxias bullocki } & \multicolumn{3}{|c|}{ Hybrids $\left(\mathrm{F}_{1}\right)$} \\
\hline & SD & $\mathrm{CR}$ & Type & $\mathrm{RL}$ & SD & Type & RL & $\mathrm{CR}$ & Type \\
\hline 1 & $66.80 \pm 8.20$ & $1.40 \pm 0.20$ & $\mathrm{~m}$ & $88.50 \pm 14.30$ & $1.17 \pm 0.10$ & $\mathrm{~m}$ & $81.90 \pm 18.60$ & $1.47 \pm 0.43$ & $\mathrm{~m}$ \\
\hline 2 & $60.50 \pm 9.80$ & $1.31 \pm 0.15$ & $\mathrm{~m}$ & $78.83 \pm 12.71$ & $1.47 \pm 0.43$ & $\mathrm{~m}$ & $58.10 \pm 8.20$ & $1.53 \pm 0.42$ & $\mathrm{~m}$ \\
\hline 3 & $56.00 \pm 8.20$ & $1.28 \pm 0.38$ & $\mathrm{~m}$ & $70.33 \pm 7.57$ & $1.23 \pm 0.16$ & $\mathrm{~m}$ & $51.90 \pm 8.80$ & $1.54 \pm 0.30$ & $\mathrm{~m}$ \\
\hline 4 & $51.00 \pm 7.70$ & $1.20 \pm 0.21$ & $\mathrm{~m}$ & $63.66 \pm 5.03$ & $1.20 \pm 0.16$ & $\mathrm{~m}$ & $45.60 \pm 6.30$ & $1.52 \pm 0.44$ & $\mathrm{~m}$ \\
\hline 5 & $47.30 \pm 5.70$ & $1.58 \pm 0.16$ & $\mathrm{~m}$ & $57.33 \pm 11.06$ & $1.22 \pm 0.10$ & $\mathrm{~m}$ & $40.00 \pm 4.10$ & $1.45 \pm 0.46$ & $\mathrm{~m}$ \\
\hline 6 & $43.10 \pm 7.40$ & $1.37 \pm 0.17$ & $\mathrm{~m}$ & $51.50 \pm 9.17$ & $1.43 \pm 0.31$ & $\mathrm{~m}$ & $35.00 \pm 15.80$ & $1.56 \pm 0.16^{*}$ & $\mathrm{~m}$ \\
\hline 7 & $40.60 \pm 6.20$ & $2.50 \pm 0.09$ & $\mathrm{~m}$ & $49.00 \pm 6.92$ & $1.53 \pm 0.18$ & $\mathrm{~m}$ & $95.10 \pm 24.30$ & $1.66 \pm 0.26$ & $\mathrm{sm}$ \\
\hline 8 & $35.80 \pm 7.50$ & $1.73 \pm 0.36^{*}$ & $\mathrm{sm}$ & $46.66 \pm 7.23$ & $1.47 \pm 0.17$ & $\mathrm{~m}$ & $69.90 \pm 12.00$ & $1.76 \pm 0.52$ & $\mathrm{sm}$ \\
\hline 9 & $30.00 \pm 6.50$ & $1.68 \pm 0.23$ & $\mathrm{sm}$ & $46.83 \pm 7.65$ & $1.29 \pm 0.18$ & $\mathrm{~m}$ & $63.10 \pm 10.70$ & $2.57 \pm 0.23$ & $\mathrm{sm}$ \\
\hline 10 & $47.50 \pm 12.70$ & $\infty$ & $\mathrm{t}$ & $46.33 \pm 6.65$ & $1.71 \pm 0.07$ & $\mathrm{sm}$ & $48.40 \pm 7.00$ & $1.71 \pm 0.23$ & $\mathrm{sm}$ \\
\hline 11 & $44.00 \pm 11.00$ & $\infty$ & $\mathrm{t}$ & $45.66 \pm 5.50$ & $1.83 \pm 0.59$ & $\mathrm{sm}$ & $43.10 \pm 6.80$ & $1.68 \pm 0.38$ & $\mathrm{sm}$ \\
\hline 12 & $41.50 \pm 8.50$ & $\infty$ & $\mathrm{t}$ & $39.00 \pm 5.29$ & $1.68 \pm 0.51 *$ & $\mathrm{sm}$ & $58.80 \pm 14.10$ & $\infty$ & $\mathrm{t}$ \\
\hline 13 & $39.50 \pm 7.80$ & $\infty$ & $\mathrm{t}$ & $37.16 \pm 6.17$ & $1.70 \pm 0.49$ & $\mathrm{sm}$ & $52.50 \pm 11.80$ & $\infty$ & $\mathrm{t}$ \\
\hline 14 & $36.60 \pm 5.60$ & $\infty$ & $\mathrm{t}$ & $60.83 \pm 5.34$ & $\infty$ & $\mathrm{t}$ & $50.00 \pm 11.80$ & $\infty$ & $\mathrm{t}$ \\
\hline 15 & $34.40 \pm 3.00$ & $\infty$ & $\mathrm{t}$ & $58.00 \pm 25.23$ & $\infty$ & $\mathrm{t}$ & $46.30 \pm 10.90$ & $\infty$ & $\mathrm{t}$ \\
\hline 16 & $32.00 \pm 3.70$ & $\infty$ & $\mathrm{t}$ & $57.33 \pm 4.78$ & $\infty$ & $\mathrm{t}$ & $40.00 \pm 7.70$ & $\infty$ & $\mathrm{t}$ \\
\hline 17 & $29.50 \pm 4.80$ & $\infty$ & $\mathrm{t}$ & $52.83 \pm 2.46$ & $\infty$ & $\mathrm{t}$ & $33.70 \pm 6.80$ & $\infty$ & $\mathrm{t}$ \\
\hline 18 & $26.70 \pm 3.50$ & $\infty$ & $\mathrm{t}$ & $46.66 \pm 5.50$ & $\infty$ & $\mathrm{t}$ & $32.10 \pm 6.50$ & $\infty$ & $\mathrm{t}$ \\
\hline 19 & $24.40 \pm 3.70$ & $\infty$ & $\mathrm{t}$ & $43.33 \pm 9.07$ & $\infty$ & $\mathrm{t}$ & $27.80 \pm 7.50$ & $\infty$ & $\mathrm{t}$ \\
\hline 20 & $22.50 \pm 4.50$ & $\infty$ & $\mathrm{t}$ & $35.00 \pm 9.98$ & $\infty$ & $\mathrm{t}$ & $20.90 \pm 4.80$ & $\infty$ & $\mathrm{t}$ \\
\hline
\end{tabular}

* Show the position of the secondary constriction.

bands is less marked in the pair 1,18 . Thin heterochromatic bands can be discerned at some telomeres, especially in the pairs 6, 9, 16,17, 18 (Fig. 2a'). The active AgNOR were not detectable in the chromosomes of this species.

\section{B. bullocki: Karyotype (redescription)}

The analysis of 45 metaphasic plates obtained from animals of two different populations showed that this species has $2 \mathrm{n}$ of 40 in both sexes. The chromosome morphology comprises 26 biarmed and 14 monoarmed. The pairs 1 to 9 are metacentric, the pairs 10 to 13 are submetacentrics, and the pairs 14 to 20 are telocentric (Fig. 2b, Table 1). The fundamental number (NF) is 66. No differences were detected between the Valdivia and Chada populations.

\section{B. bullocki: C-banding and Ag-NORs}

In this species the $\mathrm{C}$-banded karyotype presented centromeric heterochromatin in most of the chromosome pairs, except in the pairs $3,12,19$. The intensity of stained bands is less marked in the pairs $2,3,10$. The pairs $9,11,12,13$ present the large arm totally heterochromatic. The pair 15 presents a polymorphism in the pattern of heterochromatin (Fig. $2 b^{\prime}$ ). One homologous of this pair has a heterochromatic block near of the centromere, and another one in the telomeric position. The active AgNOR sites are located in the short arm of the pair $12 \mathrm{sm}$ and in the pair $15 \mathrm{t}$ (Fig. 2d).

\section{Hybrid chromosomes:}

The analysis of 59 metaphasic plates showed that the modal diploid number in both sexes is $2 n=38+1$ (Fig. 1C, Table 1). This number of chromosomes was observed in 44 metaphasic plates, and 21 biarmed and 18 monoarmed chromosomes form, the karyotype. The measurements carried out in 10 metaphasic plates showed that the biarmed chromosome pairs 1 to 6 are metacentric and 
the pairs 7 to 11 are submetacentrics. The pairs 12 to 20 are telocentric, and the fundamental number (FN) is 62 . The chromosome pair number $2 \mathrm{~m}$ has no homologous, and a secondary constriction is present in the short arm of the pair $6 \mathrm{~m}$ (Fig. 2c, Table 2).

\section{Discussion}

According to our results the 2 nominal species of Brachygalaxias (B. gothei and B. bullocki) share the same number of chromosome $(2 n=40)$. Campos $(1972)$ described the chromosomes of $B$. bullocki, and his results $(2 \mathrm{n}=38, \mathrm{FN}=64)$ were different to those reported in this study $(2 \mathrm{n}=40$, $\mathrm{FN}=66$ ). The $2 \mathrm{n}=40$ represent the highest number found hitherto in species of the Galaxiidae family in Chile e.g. Galaxias maculatus $2 \mathrm{n}=22$, G. platei $2 \mathrm{n}=30$ (Campos 1972), and according to Klinkhardt (1997) this number is distinctive for Brachygalaxias among the salmoniform fishes. These values are also near to the highest number for the species of Galaxiidae around the world, some of which were described by Johnson et al. (1981). These authors reported a $2 \mathrm{n}=42$ to 3 species of the genus Galaxias (G. brevipinnis, G. johnstoni, G. fontanus) from Tasmania.

Galetti (1998) suggested that in the Neotropical fishes, some sister species show conspicuous differences in the karyotype structure and most often also in the number of chromosomes. In this sense, in spite that both species have the same number of chromosome $(2 \mathrm{n}=40)$, we detected important differences in the chromosome characteristics of $B$. gothei and B. bullocki. In fact, B. gothei has 9 biarmed and 11 monoarmed pairs of chromosomes, and B. bullocki has 13 biarmed and 7 monoarmed pairs.

For other hand, these differences (in FN) between both species can be explained by the addition of heterochromatin (in the pairs 9, 11, 12, 13 in B. bullocki) (King 1980), and assuming a common ancestor for both species, all these chromosomes must be originally telocentric. Additionally, in $B$. bullocki it is appreciated centromeric heterochromatin in all chromosomes, except in the pairs $3,12,19$. In contrast, $B$. gothei has a c-band only in the pairs $1,2,6,9,16,17,18$. These differences in the pattern and amount of heterochromatin found between this two species, can be explained by the euchromatic transformation concept (King 1980).

On the other hand, every diploid fish species has at least two NORs (Klinkhardt 1997). Working in cyprinid fishes Amemiya and Gold (1988) concluded that the presence of NORs close to the centromere, at the ends of the short arm of submetacentric chromosomes, could represent the plesionorphic character. In B. bullocki at the pairs $12 \mathrm{sm}$ and $15 \mathrm{t}$ were detected active NORs associated to c-heterochromatic block. In the pair 12 the NOR is located close the centromere while in the pair 15 it showed a polymorphic distribution. In this pair (15), while in one homologous the NOR appeared centromeric, in the other one was telomeric. Thus, the NOR pattern in B. bullocki could be consider a derived condition respect to that proposed by Amemiya and Gold (1988). In B. gothei the active NORs were not detected with $\mathrm{AgNO}_{3}$.

Thus, in opposition to that concluded by Berra et al. (1995) our analyses (fundamental number, c-banding patterns, and AgNOR) clearly show that B. gothei and B. bullocki correspond to different genetic complexes supporting by this way the specific status of $B$. gothei.

In relation to the hybrids resulting from both species $\left(\mathrm{F}_{1}\right)$, they were kept alive as long as to 10 years, a period longer than normal animals, and during their entire life span they never showed any adult spawning colour and never gave rise to any descendant. Thus, it would be concluded that the hybrids are sterile. According with our results, the karyotype of the $\mathrm{F}_{1}$ presented the intermediate karyotype respect to the parents; the karyotype of the hybrids showed 11 biarmed and 9 monoarmed chromosomes. In the pair $2 \mathrm{~m}$ the loss of one homologous was detected. We have not explanation for the loose of one chromosome in the $\mathrm{F}_{1}$ generation, and we think it could be a consequence of a significant genetic divergence of the hybrid respect to the parents. Kobayashi (1997) working with amago salmon (Oncorhynchus rhodurus) and rainbow trout (O. mykiss), reported that 
some chromosomes were gradually eliminated in the hybrid development, after the first cleavage in the $F_{1}$. As in our study, this author concluded that this phenomenon was the main cause of inviability of the hybrid.

Berra et al. (1995) considered the overlap in their scatterplot of morphometrical data from $B$. gothei and B. bullocki populations, as an indirect evidence for gene flow. Based on that, these authors concluded that $B$. gothei has to be considered a junior synonym of B. bullocki. Contrary to this, our results showed clearly differences in FN, c-bands patterns, and a pronounced genetic divergence of the hybrids with respect to the parent's constitute strong direct evidence of both entities are genetically isolated. As a result of our study we conclude that B. gothei and B. bullocki are differentiated at specific level.

\section{Acknowledgements}

The authors are especially grateful to Dr. Lorena Villalobos, Dr. Ramón Formas and MSc. Pedro Quijón by their value comments on the manuscripts. Unfortunately Dr. Hugo Campos died while we wrote this paper. This work was support by the project S-91-36 of the Dirección de Investigatión de la Universidad Austral de Chile and Zoologisches Forschunsintitut and Museum Alexander Köenig.

\section{References}

Amemiya, C. T. 1990. Chromosomal NOR phenotypes of seven species of North American Cyprinidae, with comments on cytosistematic relationship of the Notropis volucellus species-group (Opsopoedus emiliae), and the genus Pteronotropis. Copeia 1990: 68-77.

-, Bickham, J. W. and Gold, J. R. 1984. A culture procedure for chromosome preparation in cyprinid fishes. Copeia 1984: $232-235$.

- and Gold, J. R. 1988. Chromosomal NORs as taxonomic and systematic characters in North American cyprinid fishes. Genetica 76: 81-90.

Arratia, G. 1981. Géneros de peces de aguas continentales de Chile. Publc. Mus. Nac. Hist. nat. 34: 1-108.

Berra, T. M., Feltes, R. M. and Ruiz, V. H. 1995. Brachygalaxias gothei from South-Central Chile, a synonym of $B$. bullocki (Osteichthyes: Galaxiidae). Ichthyol. Explor. Freshwaters 63: 227-234.

Bogart, J. P. 1970. Systematic problems in the amphibians family Leptodactylidae (Anura) as indicated by karyotype analyses. Cytogenetics 9: 369-383.

Busse, K. 1982. Brachygalaxias gothei n. sp. (Pisces: Galaxiidae) aus Chile. Bonn. Zool. Beitr. 33: 71-74.

- 1983. Galaxiiden, eine primitive Fischfamilie der Südkontinente. Aquar. Mag. 17: 141-144.

Campos, H. H. 1972. Karyology of three galaxiid fishes Galaxias maculatus, G. platei and Brachygalaxias bullocki. Copeia 1972: $368-370$.

Caputo, V., Marchegiani, F. and Olmo, E. 1996. Karyotype differentiation between two species of carangid fishes, genus Trachurus (Perciformes, Carangidae). Mar. Biol. 127: 193-199.

Cuevas, C. C. and Formas, J. R. 1996. Heteromorphic sex chromosomes in Eupsophus insularis (Amphibia: Anura: Leptodactylidae). Chrom. Res. 4: 467-470.

Galetti, P. M. 1998. Chromosome diversity in neotropical fishes. Ital. J. Zoolog. 65 (Suppl S): 53-56.

Gold, J. R., Shipley, N. S. and Powers, P. K. 1990. Improved methods for working with fish chromosomes, with a review of metaphase chromosome banding. J. Fish Biol. 37: 563-575.

Johnson, C. R., White, R. W. and Bickam, Y. A. 1981. Cytotaxonomy of seven species of Galaxias (Pisces: Galaxidae) in Tasmania. Genetica 56: 17-21.

Karakousis, R. P. and Rabova, M. 1996. NOR phenotype and C-banding study of Barbus cyclolepis from Greece. Folia Zool. 45 (Suppl 1): $77 \mathrm{ff}$.

King, M. 1980. C-banding studies on Australian hylid frogs: Secondary constriction structure and the concept of euchromatin transformation. Chromosoma 80: 191-217.

Klinkhardt, M. 1997. Some aspects of karyoevolution in fishes. Anim. Res. Dev. 47: 7-36.

Kobayashi, T. 1997. Study of biological characters and the genetics of some traits of triploid and gynogenetics diploid on salmonid fishes. 5. survival and cytological observations on early development of normal, hybrid, and gynogenetic embryos of amago salmon. Fish. Sci. 63(1): 33-36. 
Levan, A., Fredga, K. and Sandberg, A. 1964. Nomenclature for centromeric position on chromosomes. Hereditas 52: 201-220.

Phillips, R. B., Pleyte, K. A. and Ihssen, P. E. 1989. Patterns of chromosomal nucleolar organizer region (NOR) variation in fishes of the genus Salvelinus. Copeia 1989: 47-53.

Rufas, J. S., Iturra, P., De Souza, W. and Sponda, P. 1982. Simple silver staining procedures for the location of nucleolus and nucleolar organizer under light and electron microscopy. Arch Biol. 93: 697-710.

Sumner, A. T. 1972. A simple technique for demonstrating centromere heterochromatin. Exp. Cell. Res. 75: 304-306. 